\title{
A novel fungal GH30 xylanase with xylobiohydrolase auxiliary activity
}

\author{
Constantinos Katsimpouras ${ }^{1}$, Grigorios Dedes ${ }^{1}$, Nikolaos S. Thomaidis ${ }^{2}$ and Evangelos Topakas ${ }^{1,3^{*}}$
}

\begin{abstract}
Background: The main representatives of hemicellulose are xylans, usually decorated $\beta$-1,4-linked D-xylose polymers, which are hydrolyzed by xylanases. The efficient utilization and complete hydrolysis of xylans necessitate the understanding of the mode of action of xylan degrading enzymes. The glycoside hydrolase family 30 (GH30) xylanases comprise a less studied group of such enzymes, and differences regarding the substrate recognition have been reported between fungal and bacterial $\mathrm{GH} 30$ xylanases. Besides their role in the utilization of lignocellulosic biomass for bioenergy, such enzymes could be used for the tailored production of prebiotic xylooligosaccharides (XOS) due to their substrate specificity.

Results: The expression of a putative GH30_7 xylanase from the fungus Thermothelomyces thermophila (synonyms Myceliophthora thermophila, Sporotrichum thermophile) in Pichia pastoris resulted in the production and isolation of a novel xylanase with unique catalytic properties. The novel enzyme designated TtXyn30A, exhibited an endo- mode of action similar to that of bacterial GH30 xylanases that require 4-O-methyl-D-glucuronic acid (MeGlcA) decorations, in contrast to most characterized fungal ones. However, TtXyn30A also exhibited an exo-acting catalytic behavior by releasing the disaccharide xylobiose from the non-reducing end of XOS. The hydrolysis products from beechwood glucuronoxylan were MeGlcA substituted XOS, and xylobiose. The major uronic XOS (UXOS) were the aldotriuronic and aldotetrauronic acid after longer incubation indicating the ability of TtXYn30A to cleave linear parts of xylan and UXOS as well.

Conclusions: Hereby, we reported the heterologous production and biochemical characterization of a novel fungal GH30 xylanase exhibiting endo- and exo-xylanase activity. To date, considering its novel catalytic properties, TtXyn30A shows differences with most characterized fungal and bacterial GH30 xylanases. The discovered xylobiohydrolase mode of action offers new insights into fungal enzymatic systems that are employed for the utilization of lignocellulosic biomass. The recombinant xylanase could be used for the production of X2 and UXOS from glucuronoxylan, which in turn would be utilized as prebiotics carrying manifold health benefits.
\end{abstract}

Keywords: GH30 xylanase, Xylooligosaccharides, Thermothelomyces thermophila, Glucuronoxylan, Xylobiohydrolase

\section{Background}

Hemicelluloses are heterogeneous polysaccharides consisting of a $\beta-1,4-$ linked backbone of pentoses, hexoses, and sugar acids, which are usually decorated with side branches [1]. The primary hemicelluloses are xylans, mannans, arabinans, and galactans. The exact structure

\footnotetext{
*Correspondence: vtopakas@chemeng.ntua.gr

${ }^{1}$ Industrial Biotechnology \& Biocatalysis Group, School of Chemical Engineering, National Technical University of Athens, 9 Iroon Polytechniou Str., Zografou Campus, 15780 Athens, Greece

Full list of author information is available at the end of the article
}

and abundance of hemicelluloses diversify widely among different plant species and cell types with xyloglucans occurring mostly in the primary walls of dicots and conifers, while arabinoxylans dominate in commelinid monocots [2]. Softwoods contain galactoglucomannans, arabinoglucuronoxylans, arabinogalactans, xyloglucans, and other glucans. The leading representative of hardwood hemicellulose is xylan and more specifically $O$-acetyl-4-O-methylglucuronoxylan, which accounts for $80 \%$ to $90 \%$ of hardwood hemicelluloses. Hemicelluloses are also present in most agricultural wastes such as wheat 
straw, rice straw, corn stover, and sugar cane bagasse among others. Agricultural and forest residues have the potential to serve as a sustainable source of sugars that can be subsequently used as feedstock for the production of biofuels or high added-value bio-based materials.

The enzymatic breakdown of xylans, the main representatives of hemicelluloses, requires the action of a group of enzymes with various specific activities such as xylanases and $\beta$-xylosidases. The enzymes that are responsible for the degradation of xylan main chain are endoxylanases (E.C. 3.2.1.8) and they have been grouped in glycoside hydrolases families $5,8,10,11,16,30,43,51$, 98, and 141 of the CAZy database (http://www.cazy.org; Lombard et al. [3]) based on amino acid similarities and structural characteristics. Xylanases belonging to GH10 and GH11 families have been widely investigated in literature with GH10 xylanases exhibiting less substrate specificity than GH11 xylanases. Therefore, the former enzymes are able to catalyze the hydrolysis of a wide spectrum of xylans, while the latter are known to preferentially cleave unsubstituted regions of arabinoxylan [4].

A less studied group of endoxylanases belongs to GH30 family. Family GH30 of the glycosyl hydrolases exhibits a wide diversity. Enzymes belonging to this family include $\beta$-glucosidases (3.2.1.21), $\beta$-glucuronosidases (EC 3.2.1.31), $\beta$-xylosidases (3.2.1.37), $\beta$-fucosidases (EC 3.2.1.38), glucosylceramidases (EC 3.2.1.45), $\beta-1,6-$ glucanases (EC 3.2.1.75), glucuronoarabinoxylan endo- $\beta$ 1,4-xylanase (EC 3.2.1.136), and endo- $\beta$-1,6-galactanase (EC 3.2.1.164). Furthermore, GH30 family comprise 8 subfamilies of which the subfamily 8 includes enzymes that have been shown to be appendage-dependent since they act against xylan decorated with 4-O-methyl-D-glucuronic acid (MeGlcA) side substituents [5, 6]. Bacterial xylanases such as XynA from Erwinia chrysanthemi and XynC from Bacillus subtilis belong to GH30_8 family and they appeared to be functional against glucuronoxylan, while these enzymes do not act, or act orders of magnitude slower, against oligosaccharides or polysaccharides that are not decorated with MeGlcA [7-9]. Similar GH30_8 xylanases that have been characterized are Xyn5B from Bacillus sp. strain BP-7, Xyn30D from Paenibacillus barcinonensis, BsXyn30 from Bacillus subtilis LC9, and StXyn30A from Streptomyces turgidiscabies [10-13]. However, the CpXyn30A from Clostridium papyrosolvens has been reported to hydrolyze glucuronoxylan, neutral xylooligosaccharides and wheat arabinoxylan, probably due to a loss of amino acid sequence conservation in a region involved in glucuronic acid (GlcA) recognition [14]. Moreover, a GH30_8 xylanase from Clostridium acetobutylicum was reported as a GlcA-independent endo-xylanase that shows preference against arabinofuranose-substituted xylan chains [15].
GH30 xylanases of fungal origin have also been shown to differ compared to those from bacteria as they exhibit a broader substrate specificity. The xylanases XynD from Bispora sp. and XYN IV from Trichoderma reesei have been reported to be active also on arabinoxylan, thus exhibiting different catalytic properties from bacterial GH30 xylanases [16, 17]. Nevertheless, Biely et al. [5] described the expression of a novel GH30 xylanase from T. reesei designated XYN VI that exhibited catalytic properties almost identical to bacterial GH30 xylanases [5].

The specificity of GH30 endoxylanases renders them a key tool for the generation of uronic xylooligosaccharides (UXOS) that could function as prebiotic compounds and preserve a balanced intestinal microflora. Endoxylanases, in general, comprise significant tools for the production of tailored, prebiotic oligosaccharides [18]. Production of UXOS from biomass has been reported from sweet sorghum and sweetgum wood, using GH11 and GH30 xylanases from Bacillus subtilis [19, 20]. Moreover, Valls et al. [21] investigated the antioxidant activity of XOS produced from beechwood glucuronoxylan using a GH30 xylanase from $P$. barcinonensis and found out that it was significantly higher than that from XOS produced by a GH10 xylanase.

Enzymes from thermophilic microorganisms are of great biotechnological and industrial interest as they exhibit improved robustness and are able to endure more severe process conditions [22]. Thermothelomyces thermophila (synonyms Myceliophthora thermophila, Sporotrichum thermophile) is a thermophilic fungus that possesses an impressive arsenal of hemicellulolytic enzymes, which are necessary to overcome the recalcitrance of plant cell wall. The sequencing and annotation of $T$. thermophila genome revealed a great number of putative cell wall-degrading enzymes [23]. Ten xylanases, with four of them belonging to GH10 family and the rest to GH11 family, have been purified and characterized from multienzyme preparations of $T$. thermophila modified strains [24, 25]. Two genes encode putative GH30 xylanolytic enzymes, yet the characterization of a GH30 xylanase from $T$. thermophila has not been conducted [23].

In the present study, we reported the cloning of the $T$. thermophila ex30a gene and its heterologous expression using the $P$. pastoris expression system. The biochemical characterization and determination of the recombinant enzyme's catalytic properties were conducted as well. The findings revealed that the gene codes for a T. thermophila GH30 xylanase, dubbed TtXyn30A, which functions not only as an appendage-dependent GH30 endo-xylanase but also shows exo-xylanase activity from the non-reducing end liberating xylobiose (X2) from linear and substituted xylan chains. During the publication process of the 
present study, a novel GH30_7 xylanase from the cellulolytic fungus Talaromyces cellulolyticus has been reported to possess both endo-glucuronoxylan and exo-xylobiohydrolase activities, confirming the discovered unique mode of action [26].

\section{Results}

\section{Sequence analysis of $T$ XXyn30A}

The putative endo-xylanase gene encodes a protein of 477 amino acids including a secretion signal peptide of 19 amino acids (MYSLLIALLCAGTAVDAQA) as it was predicted by SignalP 4.0 server. A sequence analysis using the InterProScan server showed that the enzyme involves a GH30 catalytic domain, while it is not modular. The mature protein comprises 458 amino acids and the theoretical MW and $\mathrm{p} I$ were calculated using the ExPASY ProtParam tool and were found to be 48,976.2 Da and 5.5 , respectively. The putative xylanase was cloned and expressed using the gene ex30a, which was synthesized as codon optimized for expression in P. pastoris omitting the signal peptide and its 3 introns.

The sequence homology values between the mature protein $T t X y n 30 \mathrm{~A}$ and other GH30 xylanases, either of bacterial or fungal origin, were calculated and are presented in Table 1 . The putative xylanase exhibited amino acid sequence identity from 22 to $24 \%$ and similarity from 40 to $45 \%$ in comparison with bacterial GH30 xylanases. Higher homology was exhibited compared with fungal GH30 xylanases. Tt Xyn30A showed amino acid sequence identities of $39.7 \%, 38.5 \%, 44.2 \%$, and $43.8 \%$ with four xylanases from microorganisms Bispora sp. MEY-1, T. reesei, T. cellulolyticus, and Penicillium purpurogenum, respectively $(59.2 \%, 53.9 \%, 61.8 \%$, and $62.5 \%$ similarity, respectively). The XYN VI from $T$. reesei [5] was the closest characterized sequence homolog with $44.3 \%$ sequence identity (61.4\% sequence similarity).

\section{Heterologous expression and physicochemical properties of $T$ XXyn30A}

The purified xylanase TtXyn30A exhibited an estimated MW of $61 \mathrm{kDa}$ as indicated by SDS-PAGE analysis (Fig. 1a). Furthermore, the $\mathrm{p} I$ of $T t \mathrm{Xyn} 30 \mathrm{~A}$ was experimentally determined by IEF-PAGE and was found to be in the range of 5.3-6.2 (Fig. 1b). The MW of the purified TtXyn30A was higher than the calculated value of $51.7 \mathrm{kDa}$, including the myc epitope and the polyhistidine tag that contribute to the increase of the MW by about $2.5 \mathrm{kDa}$. One $\mathrm{N}$-glycosylation site was predicted using the NetNGlyc 1.0 server at residue N176 and might be responsible for the observed difference in MW of TtXyn30A. Additionally, four potential O-glycosylation sites were identified using the NetOGlyc 4.0 server ( 3 Ser and $1 \mathrm{Thr})$. The MW of the recombinant xylanase decreased
Table 1 Identity and similarity values among the amino acid sequences of the mature xylanase TtXyn30A and other mature GH30 xylanases from different microorganisms (carbohydrate binding domains or dockerins are not included)

\begin{tabular}{lll}
\hline Microorganism (GH30 xylanase) & Identity & Similarity \\
\hline Bacterial & & \\
Aeromonas caviae (XynD) & $23.4 \%(85 / 363)$ & $44.9 \%(163 / 363)$ \\
Bacillus sp. BP7 (Xyn5B) & $22.1 \%(76 / 344)$ & $40.4 \%(139 / 344)$ \\
Bacillus subtilis 168 (XynC) & $22.4 \%(77 / 344)$ & $38.7 \%(133 / 344)$ \\
Clostridium papyrosolvens & $22.4 \%(76 / 339)$ & $44.8 \%(152 / 339)$ \\
$\quad$ (CpXyn30A) & & \\
Clostridium thermocellum & $22.9 \%(75 / 327)$ & $41.9 \%(137 / 327)$ \\
$\quad$ CtXyn30A) & & \\
Erwinia chrysanthemi (XynA) & $24.3 \%(111 / 456)$ & $39.7 \%(181 / 456)$ \\
Paenibacillus barcinonensis & $24.2 \%(90 / 372)$ & $42.2 \%(157 / 372)$ \\
$\quad$ Xyn30D) & & \\
Streptomyces turgidiscabies C56 & $23.2 \%(73 / 315)$ & $42.9 \%(135 / 315)$ \\
Fungal & & \\
Bispora sp. MEY-1 (XyID) & $39.7 \%(180 / 453)$ & $59.2 \%(268 / 453)$ \\
Penicillium purpurogenum (XynC) & $43.8 \%(201 / 459)$ & $62.5 \%(287 / 459)$ \\
$\quad$ Talaromyces cellulolyticus (Xyn30B) & $44.2 \%(201 / 455)$ & $61.8 \%(281 / 455)$ \\
Trichoderma reesei (XYN IV) & $38.5 \%(153 / 397)$ & $53.9 \%(214 / 397)$ \\
Trichoderma reesei (XYN VI) & $44.3 \%(200 / 451)$ & $61.4 \%(277 / 451)$ \\
\hline
\end{tabular}

by about $9 \mathrm{kDa}$ after treatment with Endoglycosidase $\mathrm{H}$ (EndoH), which is an indication of $\mathrm{N}$-glycosylation (Fig. 1a).

\section{Biochemical characterization of purified $T t$ Xyn30A}

TtXyn30A optimum conditions were investigated using beechwood glucuronoxylan as substrate. The optimum activity was observed at $\mathrm{pH} 4.0$, while the enzyme maintained more than $88 \%$ of its initial activity at $\mathrm{pH}$ range from 3.5 to 4.5 (Additional file 1: Figure S1a). Moreover, TtXyn30A maintained about $77 \%$ of its initial activity at $\mathrm{pH}$ 5.0, while a sharp loss in enzyme's activity was noted at $\mathrm{pH} 3.0$ and at $\mathrm{pH}$ values greater than $5.0(10 \%$ of its initial activity at $\mathrm{pH} 6.0$ ). The xylanase was stable at $\mathrm{pH}$ range from 3.0 to 9.0 after a 24 -h incubation, maintaining more than $97 \%$ of its initial activity (Additional file 1: Figure S2).

Optimal temperature was achieved at $50{ }^{\circ} \mathrm{C}$ and $\mathrm{pH} 4.0$, while the enzyme lost rapidly its activity at temperatures over $55{ }^{\circ} \mathrm{C}$ (Additional file 1: Figure S1b). In addition, $T t$ Xyn30A was adequately active even at $40^{\circ} \mathrm{C}$ and $45^{\circ} \mathrm{C}$, where it retained more than $70 \%$ and $88 \%$ of its initial activity, respectively. Beechwood xylan hydrolysis rate at $50{ }^{\circ} \mathrm{C}$ and $\mathrm{pH} 4.0$ is shown in Additional file 1: Figure S3. A linear increase of the hydrolysis rate was observed for the first $4 \mathrm{~h}$, indicating the stability of the recombinant 

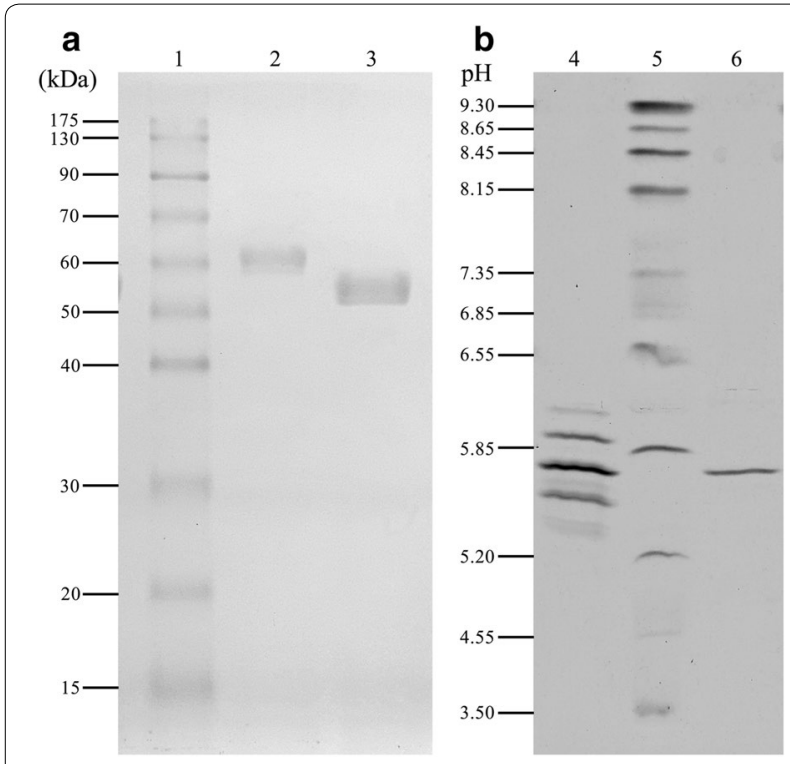

Fig. 1 SDS-PAGE (a) and IEF (b) of TtXyn30A. a LMW standard protein markers (1), purified TtXyn30A (2), and TtXyn30A after enzymatic treatment with EndoH (3). b Purified TtXyn30A (4), standard protein markers with p/ range 3.0-10.0 (5), and TtXyn30A after enzymatic treatment with EndoH (6)

xylanase at the optimum temperature. When it comes to the hydrolysis rate of wheat arabinoxylan, it was orders of magnitude lower than that achieved during glucuronoxylan hydrolysis.

The specific activity of recombinant TtXyn30A was investigated using a variety of substrates at $50{ }^{\circ} \mathrm{C}$ and $\mathrm{pH}$ 4.0. The highest specific activity was observed with beechwood glucuronoxylan and was found to be $6 \mathrm{U} \mathrm{mg}^{-1}$. Against wheat arabinoxylan the specific activity was much lower $\left(0.07 \mathrm{U} \mathrm{mg}^{-1}\right)$, indicating a preference for substrates substituted with MeGlcA. The enzyme showed no activity against carob galactomannan, konjac glucomannan, and barley $\beta$-glucan. The recombinant TtXyn30A exhibited a catalytic efficiency $k_{\text {cat }} / K_{\mathrm{m}}$ of $254.8 \mathrm{~mL} \mathrm{mg} \mathrm{min}^{-1}$ $\left(K_{\mathrm{m}}=1.7 \pm 0.1 \mathrm{mg} \mathrm{mL}^{-1}\right.$ and $\left.V_{\max }=7.1 \pm 0.2 \mathrm{U} \mathrm{mg}^{-1}\right)$.

The presence of $\mathrm{Co}^{2+}, \mathrm{Cu}^{2+}$, and $\mathrm{Mn}^{2+}$ enhanced the activity as high as $44 \%$ at concentration of $10 \mathrm{mM}$. Furthermore, a partial inhibition, from 5 to $15 \%$, of the enzyme was observed in the presence of certain metal ions or chemical compounds at the concentration of $10 \mathrm{mM}$ (from higher inhibition to lower): EDTA $>\mathrm{Mg}^{2+}>$ Urea, $\mathrm{Zn}^{2+}>\mathrm{Fe}^{3+}$. The presence of the rest of the metal ions had little on negligible effect (Additional file 1: Table S1).

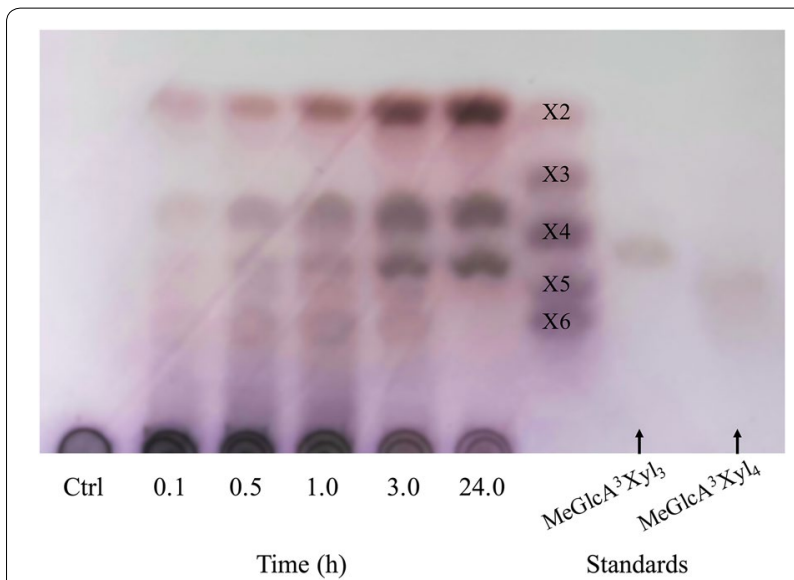

Fig. 2 TLC analysis of hydrolysis products from beechwood xylan by recombinant $T t X y n 30 A$. The reaction was carried out in $0.05 \mathrm{mM}$ citrate-phosphate buffer $\mathrm{pH} 4.0$ at $50^{\circ} \mathrm{C}$. The substrate and enzyme loadings were $5 \mathrm{mg} \mathrm{mL}^{-1}$ and $0.09 \mathrm{U} \mathrm{mL}^{-1}$, respectively. Xylooligosaccharides (DP 2-6) and aldouronic acids (aldotetrauronic and aldopentauronic acid) were used as standards

\section{Hydrolysis product analysis}

The hydrolysis products of beechwood glucuronoxylan under the action of the purified recombinant TtXyn30A were firstly analyzed by thin layer chromatography (TLC) (Fig. 2). The initial products after $0.1 \mathrm{~h}$ of enzymatic reaction seem to be a mixture of UXOS and xylobiose (X2). At longer incubation times the longer chain UXOS were hydrolyzed into shorter chain ones with simultaneous liberation of X2, while xylose was absent. The most prominent hydrolysis products after $24 \mathrm{~h}$ of incubation were the $\mathrm{MeGlcA}^{2} \mathrm{Xyl}_{2}$, the MeGlcA ${ }^{2} \mathrm{Xyl}_{3}$ that were identified by HILIC/ESI-QTOF-MS (superscript states the position of the MeGlcA, while the subscript denotes the number of xylose residues; Additional file 1: Figure S4a, b), and the X2. Moreover, analysis of hydrolysis products by HPAEC-PAD showed no release of other linear XOS except small amounts of $\mathrm{X} 4$ that can be attributed to transglycosylation activity (Fig. 3). After incubation with $\beta$-xylosidase, only the MeGlcA ${ }^{2} \mathrm{Xyl}_{2}$ was detected, and the $\mathrm{X} 2$ was converted to xylose (Additional file 1: Figure S4c).

The activity of the recombinant enzyme against linear XOS was also investigated. X3 and X5 were hydrolyzed to xylose and X2, while the hydrolysis of X4 and X6 led to the release of only X2 after $18 \mathrm{~h}$ of incubation (Fig. 4). In order to find out whether the enzyme works from the reducing or the non-reducing end, the $\mathrm{XOS}$ were treated with $\mathrm{NaBH}_{4}$. The $\mathrm{NaBH}_{4}$ reduced XOS were incubated with the TtXyn30A for $18 \mathrm{~h}$ revealing the same hydrolysis pattern as in the case of regular XOS (Fig. 5). 


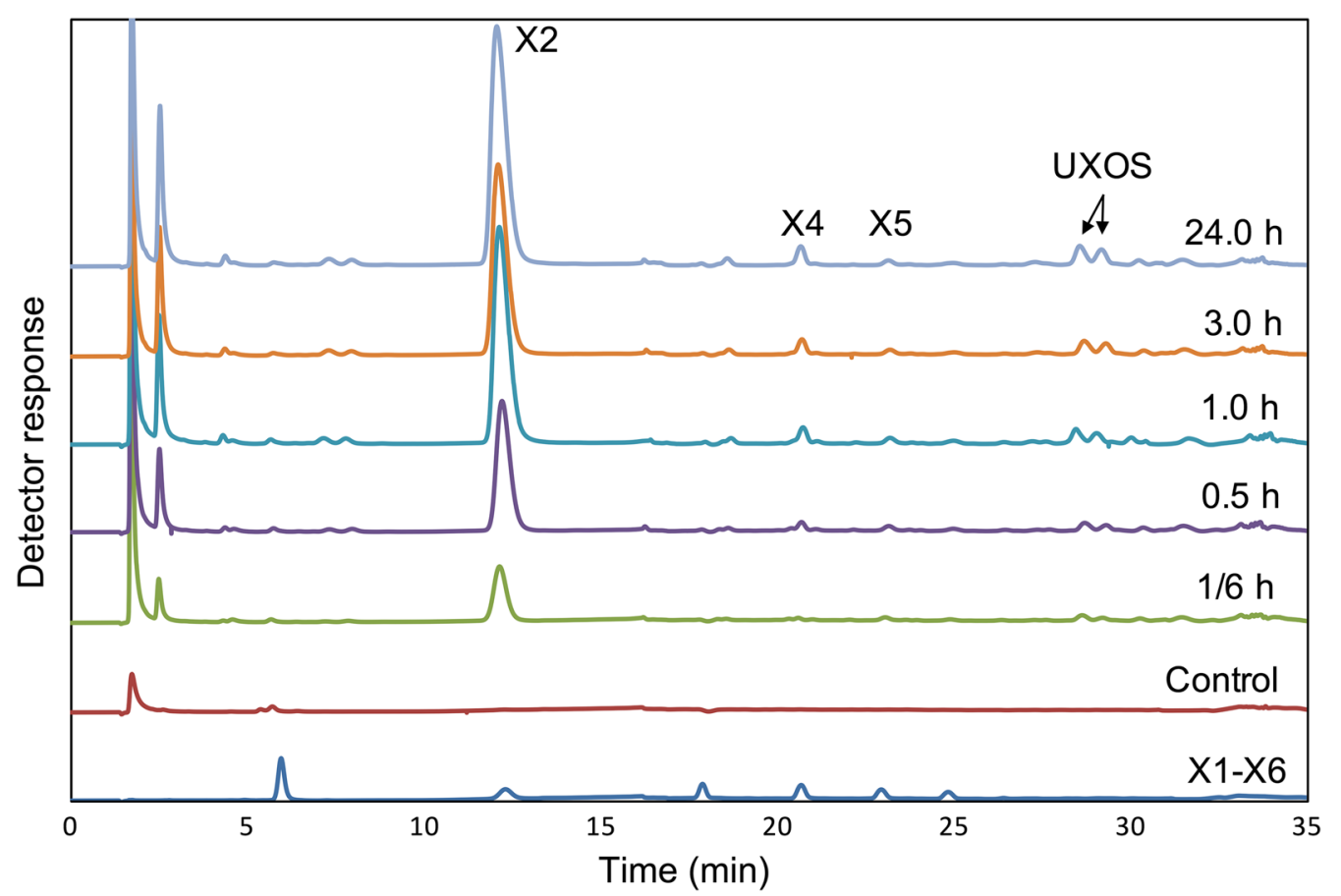

Fig. 3 Time course of the hydrolysis products of beechwood glucuronoxylan under the action of the recombinant TtXyn30A by HPAEC-PAD. The reaction was carried out in $0.05 \mathrm{mM}$ citrate-phosphate buffer $\mathrm{pH} 4.0$ at $50^{\circ} \mathrm{C}$. The substrate and enzyme loadings were $5 \mathrm{mg} \mathrm{mL}^{-1}$ and 0.09 $U \mathrm{~mL}^{-1}$, respectively

Analysis of hydrolysis products by HILIC/ESI-QTOFMS confirmed the observations that were made by TLC. The main UXOS that were detected up to $1 \mathrm{~h}$ of incubation of beechwood glucuronoxylan under the action of $T t$ Xyn30A were $\mathrm{MeGlcA}^{2} \mathrm{Xyl}_{2}$ to $\mathrm{MeGlcA}^{2} \mathrm{Xyl}_{8}$, while $\mathrm{X} 2$ was also liberated. After $3 \mathrm{~h}$ of enzymatic hydrolysis, MeGlcA ${ }^{2} \mathrm{Xyl}_{2}$ to $\mathrm{MeGlcA}^{2} \mathrm{Xyl}_{4}$ were detected, while after $24 \mathrm{~h}$ of incubation the liberation of only $\mathrm{MeGlcA}^{2} \mathrm{Xyl}_{2}$ and $\mathrm{MeGlcA}^{2} \mathrm{Xyl}_{3}$, alongside X2, was noted (Additional file 2: Figure $\mathrm{S} 1$ ).

\section{Discussion}

The $P$. pastoris expression system was employed to produce the recombinant GH30 xylanase TtXyn30A from the filamentous ascomycete T. thermophila. This specific expression system has been successfully used for the production of two more fungal GH30 xylanases, the XylD from Bispora sp. MEY-1 [17] and XynC from Penicillium purpurogenum [27]. P. pastoris comprise a well-known expression system as its properties such as the efficient enzyme production, the fast growth in inexpensive media, and the appropriate folding and transportation of proteins render it an excellent tool for recombinant protein production. In many other cases, the expression host E. coli BL21 has been used for the production of bacterial GH30 xylanases, such as the StXyn30A from
Streptomyces turgidiscabies [12], the Xyn30A from Paenibacillus favisporus [28], the Xyn30D from Paenibacillus barcinonensis [11] and the XynA from Erwinia chrysanthemi [8] among others. To date, only five fungal GH30 xylanases have been characterized, two from $T$. reesei, one from Bispora sp. MEY-1, one from P. purpurogenum and recently one from $T$. cellulolyticus $[5,16,17,26,27]$.

The calculated MW (51.7 kDa) of TtXyn30A was lower than that determined by SDS-PAGE $(61 \mathrm{kDa})$ possibly due to post-translational modifications. The $\mathrm{p} I$ determination by IEF revealed multiple protein bands in the range of 5.3-6.2, which was also an indication of protein glycosylation as different carbohydrate groups were added to the molecule. It is common for glycosylation patterns to differ between them and has been reported that proteins expressed in $P$. pastoris exhibited variation concerning the number of the mannose units that were added to the same polysaccharide chain [29]. The treatment of TtXyn30A with EndoH revealed that the difference in MW and the multiple bands in IEF-PAGE were a result of $\mathrm{N}$-glycosylation. The MW of the treated $T t$ Xyn30A was almost identical with the calculated one, while a single band appeared at $\mathrm{pH}$ value 5.6 (Fig. 1a, b).

The hydrolytic activity of the recombinant enzyme was investigated against beechwood glucuronoxylan, wheat arabinoxylan, and other substrates. The purified 


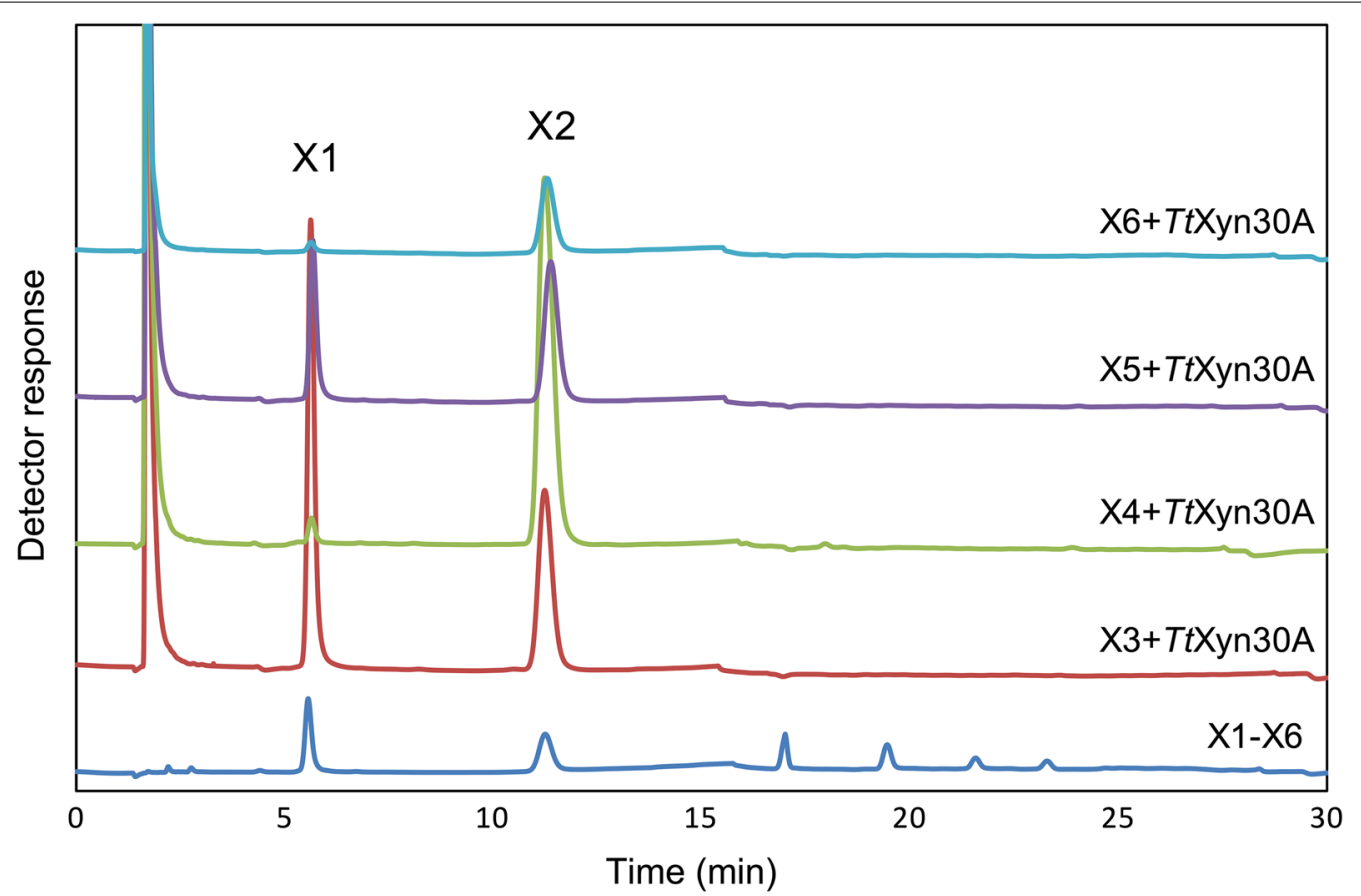

Fig. 4 Analysis of the hydrolysis products from xylooligosaccharides (X3-X6) using HPAEC-PAD under the action of TtXyn30A. The reactions were carried out in $0.05 \mathrm{mM}$ citrate-phosphate buffer $\mathrm{pH} 4.0$ at $50^{\circ} \mathrm{C}$ for $18 \mathrm{~h}$, and the enzyme loading was $0.09 \mathrm{U} \mathrm{mL}^{-1}$

TtXyn30A showed the highest activity toward beechwood glucuronoxylan, which consists of a $\beta$-1,4-linked xylose backbone decorated with the methylated form of GlcA attached directly to the main chain at xylose C2 (about 13\% MeGlcA substitution). However, the specific activity against wheat arabinoxylan, a xylan without MeGlcA substituents along the main chain, was about two orders of magnitude lower than that achieved in the case of beechwood xylan. Bacterial GH30 xylanases are active only against glucuronoxylan, attacking the main chain dependently on the presence of MeGlcA substituents $[7,9]$. In contrast, fungal GH30 xylanases seem to exhibit a wider specificity by being active on both glucuronoxylans and arabinoxylans. XynC from $P$. purpurogenum was active on birchwood xylan and rye arabinoxylan exhibiting higher specific activities of $37 \mathrm{U} \mathrm{mg}^{-1}$ and $17 \mathrm{U} \mathrm{mg}^{-1}$, respectively [27]. Two other fungal GH30 xylanases showed similar specificity. XylD from Bispora sp. MEY-1 demonstrated high activity on beechwood xylan and wheat arabinoxylan as well as XYN IV from $T$. reesei $[16,17]$. However, the XYN VI from T. reesei was the first GH30 xylanase that exhibited catalytic properties that resembled those of bacterial GH30 xylanases [5]. XYN VI showed high specific activity only against xylans containing MeGlcA side substituents, while specific activity less than $0.05 \mathrm{U} \mathrm{mg}^{-1}$ was determined for wheat arabinoxylan, and rhodymenan, which is a linear soluble $\beta-1,3-\beta-1,4$-xylan. The catalytic properties that were observed for the TtXyn30A were similar to those of XYN $\mathrm{VI}$ as specific activity of only $0.07 \mathrm{U} \mathrm{mg}^{-1}$ was achieved against arabinoxylan after long incubation, unlike beechwood xylan where about 100 -fold higher specific activity was noted.

The incubation of beechwood glucuronoxylan with $T t X y n 30 \mathrm{~A}$ resulted in a mixture of UXOS and X2. Furthermore, the conversion of every generated UXOS to MeGlcA ${ }^{2} \mathrm{Xyl}_{2}$ upon incubation with a $\beta$-xylosidase indicated that the recombinant TtXyn30A acts on the second glycosidic bond from the MeGlcA substitution and toward the reducing end of the polysaccharide in the same manner as the bacterial GH30s. The major products after longer incubation times were found to be $\mathrm{X} 2$, $\mathrm{MeGlcA}^{2} \mathrm{Xyl}_{2}$, and $\mathrm{MeGlcA}^{2} \mathrm{Xyl}_{3}$ (after $24 \mathrm{~h}$ of enzymatic hydrolysis). In addition, during the hydrolysis of glucuronoxylan, a slight production of $\mathrm{X} 4$ was noted that can be attributed to transglycosylation activity. The formation of such products has been reported before by GH30 xylanases. The production of X4 and X6 has been described during the hydrolysis of glucuronoxylan by the recently characterized Xyn30B [26]. Moreover, the T. reesei XYN VI exhibited transglycosylation activity as the hydrolysis of X5 was accompanied by the formation of products of higher degree of polymerization (DP) [5]. The increase in $\mathrm{MeGlcA}^{2} \mathrm{Xyl}_{2}$ concentration after longer incubation 

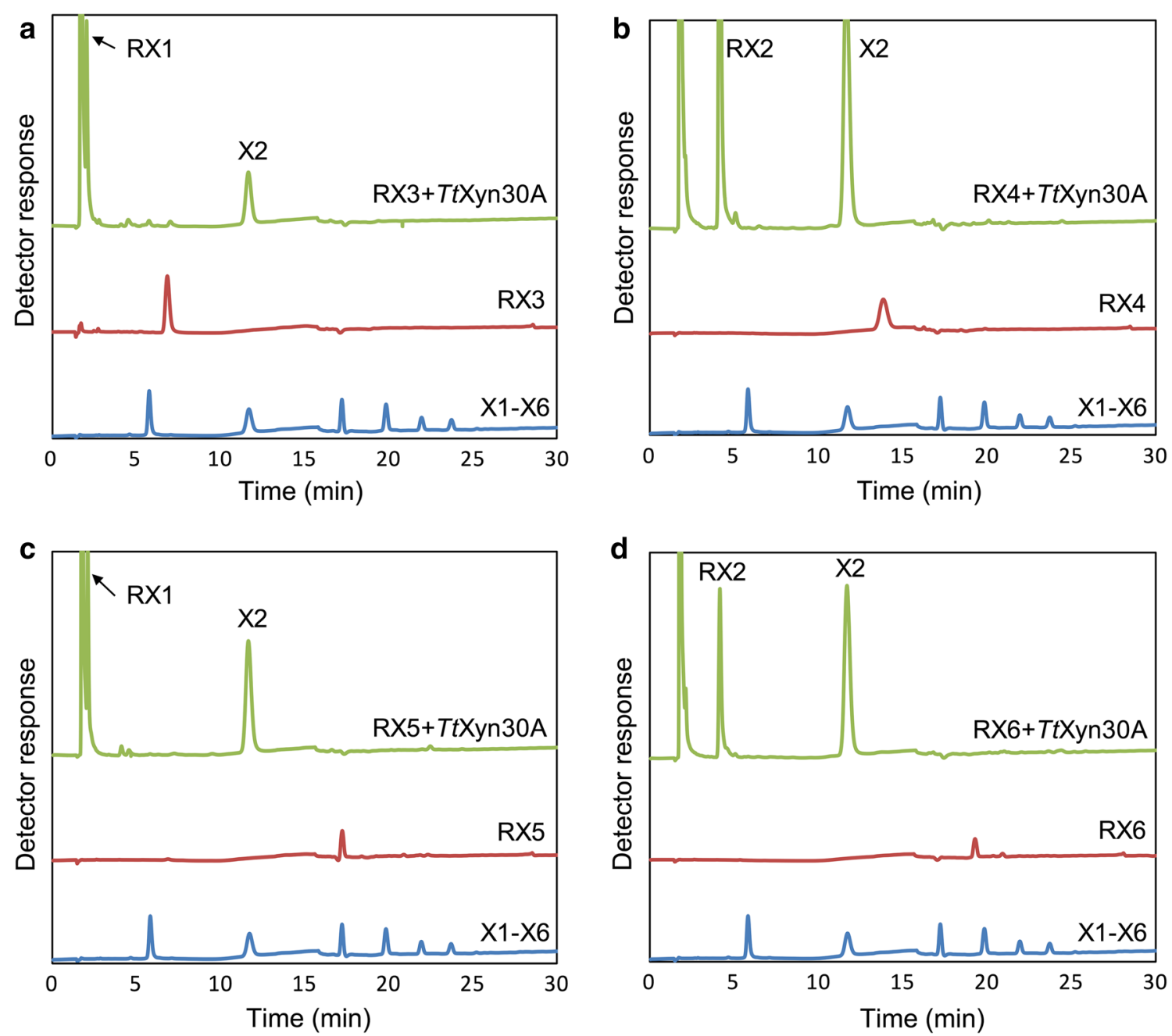

Fig. 5 Analysis of the hydrolysis products liberated from $\mathrm{NaBH}_{4}$ reduced XOS (RX; DP 3-6) using HPAEC-PAD. Hydrolysis products liberated from a RX3, b RX4, c RX5, and $\mathbf{d}$ RX6. The reactions were carried out in $0.05 \mathrm{mM}$ citrate-phosphate buffer $\mathrm{pH} 4.0$ at $50^{\circ} \mathrm{C}$ and the enzyme loading was $0.09 \mathrm{U} \mathrm{mL}^{-1}$

indicated the capability of TtXyn30A to hydrolyze the glycosidic bond to the xylose residue decorated with MeGlcA. The aldouronic acid MeGlcA ${ }^{2} \mathrm{Xyl}_{2}$ was also one of the major products from glucuronoxylan hydrolysis after long incubation times with XYN VI from T. reesei [5]. However, the action of XYN VI against glucuronoxylan also led to the release of a mixture of linear XOS in contrast to the case of TtXyn30A where only X2 was released. In an attempt to explain the release of only X2 from the generated UXOS during the glucuronoxylan hydrolysis, the activity of TtXyn30A against linear XOS was investigated. The release of only X2 from X4 and X6, and xylose and $\mathrm{X} 2$ from $\mathrm{X} 3$ and $\mathrm{X} 5$ suggested that the enzyme cleaved X2 units from the XOS chain. The TtXyn30A exhibited the same hydrolysis pattern against the
$\mathrm{NaBH}_{4}$ reduced XOS indicating that the enzyme works processively from the non-reducing end of the XOS chain releasing $\mathrm{X} 2$. The proposed mode of action is presented in Fig. 6a. The recombinant xylanase initially generates a mixture of UXOS as a result of an endo-action, while due to its xylobiohydrolase activity from the non-reducing end of the generated UXOS, X2 and two specific aldouronic acids are produced. It seems that when xylose residues of UXOS are an even number the main product is $\mathrm{MeGlcA}^{2} \mathrm{Xyl}_{2}$, which was the shortest UXOS from the reaction mixture. In the case when the UXOS contain an odd number of xylose residues the main product is the aldotetrauronic acid $\mathrm{MeGlcA}^{2} \mathrm{Xyl}_{3}$ (Fig. 6b). Similarly, the recently characterized $\mathrm{Xyn} 30 \mathrm{~B}$ from $T$. cellulolyticus released X2 with simultaneous increase in $\mathrm{MeGlcA}^{2} \mathrm{Xyl}_{2}$ 


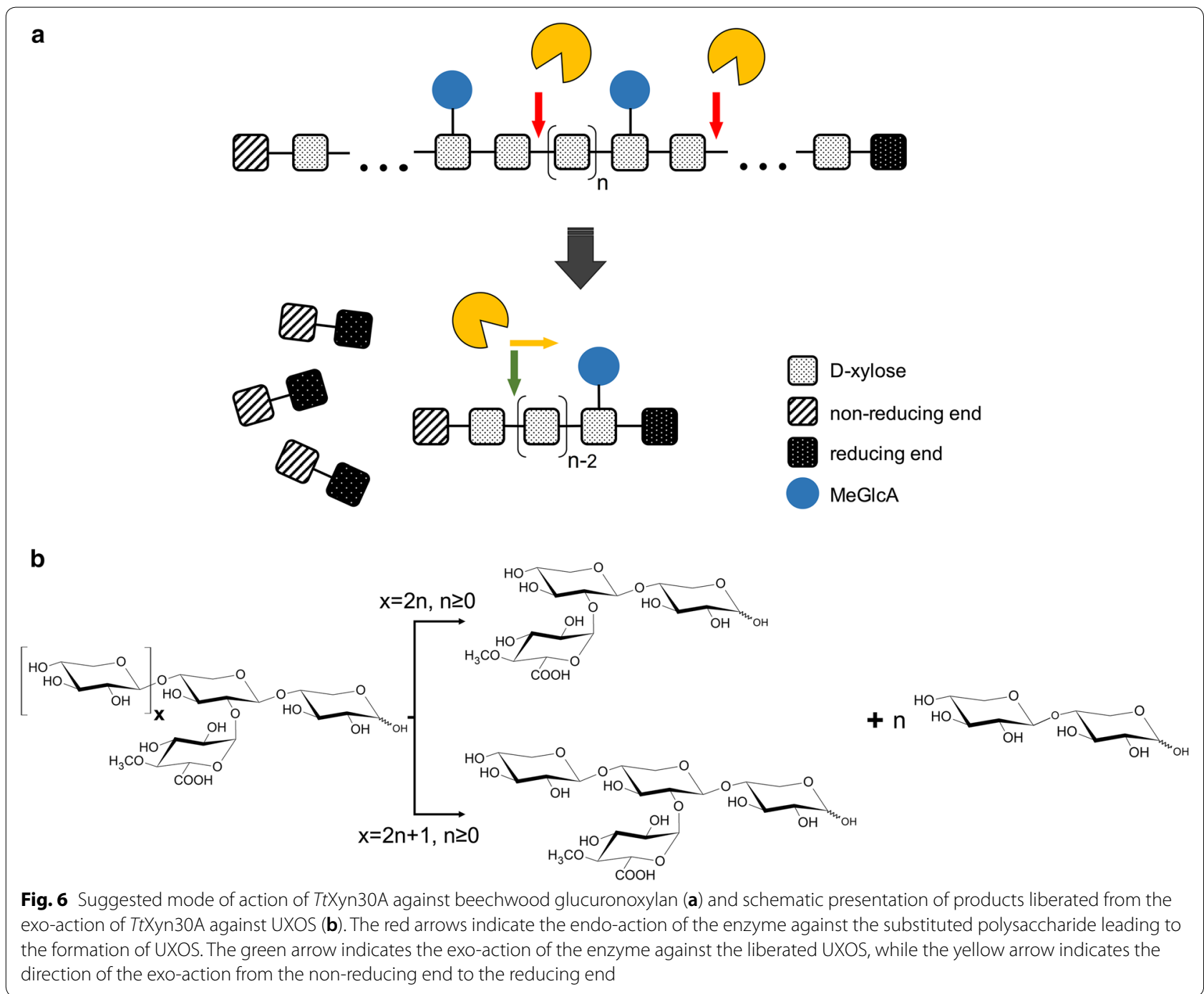

and MeGlcA ${ }^{2} \mathrm{Xyl}_{3}$ after prolonged incubation with beechwood xylan suggesting an exo-biohydrolase activity [26]. A similar mode of action to these bifunctional xylanases has been observed in processive GH5 endoglucanases, such as Cel5A from Gloeophyllum trabeum, revealing the presence of processive cellulases in brown rot fungi [30]. These processive endoglucanases cleave cellulose internally, while releasing soluble oligosaccharides, such as cellobiose, before detaching from polysaccharides. The xylanase XYN IV from T. reesei also exhibited both endo- and exo-xylanase activity but in a different manner compared to $T t X y n 30 A$. The XYN IV attacked linear $\mathrm{XOS}$ at the first glycosidic linkage from the reducing end liberating xylose, while it did not recognize MeGlcA as substrate specificity determinant. The mode of action of XYN IV suggested that the enzyme aims at liberating xylose from the reducing end of decorated XOS that show resistance to the action of $\beta$-xylosidases or other endoxylanases [16].

The optimum activity of TtXyn30A was observed at $50{ }^{\circ} \mathrm{C}$ and $\mathrm{pH}$ 4.0. The highest optimum temperature has been reported for CtXyn30A from $C$. thermocellum $\left(70^{\circ} \mathrm{C}\right)$, while $\mathrm{GH} 30$ xylanases from B. subtilis, P. flavisporus, and Bispora sp. possess temperature optima of $65^{\circ} \mathrm{C}$ $[7,17,28,31]$. Unlike bacterial GH30 xylanases (optimal $\mathrm{pH}$ at 6.0-6.5), $\mathrm{pH}$ optima for the fungal ones are more acidic in the range from $\mathrm{pH} 3.0$ to 5.0.

The reveal of 3D crystal structures of GH30 xylanases is of utmost importance in order to elucidate the interaction between these enzymes and their substrate; especially in the case of bacterial GH30 xylanases where the recognition of the GlcA or MeGlcA substituent is crucial for their activity. To this day, 3D structures for five bacterial GH30 xylanases, members of subfamily 8 , have been determined and more specifically for XynC from $B$. 


\section{(See figure on next page.)}

Fig. 7 Sequence alignment of TtXyn30A and other GH30 xylanases, either of bacterial or fungal origin. The R46 residue (as in Xyn30B) is indicated by a blue arrow. Red arrows indicate the strictly conserved catalytic glutamate residues. The residue R293 of E. chrysanthemi XynA is indicated by a green arrow. The identical residues are shown in white on a red background, while similar residues are shown in red on a white background. Talaromyces cellulolyticus Xyn30B (GAM36763), Aeromonas caviae XynD (AAB63573.1), Bacillus sp. BP7 Xyn5B (ADM15019.1), Bacillus subtilis BsXynC (CAA97612.1), Clostridium thermocellum CtXyn30A (ABN54208.1), Clostridium papyrosolvens CpXyn30A (EGD48159.1), Erwinia chrysanthemi XynA (AAB53151.1), Paenibacillus barcinonensis Xyn30D (AEY82463.1), Bispora sp. MEY-1 XyID (ADG62369.1), Penicillium purpurogenum XynC (AKH40280), Trichoderma reesei XYN IV (AAP64786.1), Trichoderma reesei XYN VI (GORV92)

subtilis [32], XynA from E. chrysanthemi [33], CpXyn30A from C. papyrosolvens [14], Xyn30D from P. barcinonensis [34], and CtXyn30A from C. thermocellum [35]. Structural studies of XynA from E. chrysanthemi, crystallized with the aldotetrauronic acid as a ligand, revealed that a conserved arginine residue (R293) interacts with the carboxyl group of MeGlcA (ionic interaction) side substituent and contributes this way to the substrate recognition [33]. Additionally, in the case of StXyn30A from S. turgidiscabies, the catalytic residue R296 that is conserved at subsite -2 was replaced and as a result, the activity of the mutant constructs against glucuronoxylan was essentially reduced [12]. The only characterized bacterial GH30 xylanase that does not conserve this specific amino acid residue is $C p$ Xyn30A from C. papyrosolvens by having a tryptophan residue [14]. However, none of the six characterized to date fungal GH30 xylanases seem to conserve this arginine residue (green arrow; Fig. 7). During the publication process of the present study, the first crystal structure of a member of GH30_7 subfamily was reported, giving an insight on the MeGlcA recognition of the fungal xylanase counterparts. The 3D structure of Xyn30B from T. cellulolyticus, alongside site directed mutagenesis, revealed that the $\mathrm{R} 46$ residue plays a key role for the enzyme's apendage-dependent endo-mode of action against xylan [26]. The R46 residue, which is R51 in TtXyn30B, is conserved in the amino acid sequences of all characterized GH30_7 glucuronoxylanases. However, XYN IV, which does not require the MeGlcA as substrate specificity determinant, does not have the arginine residue (I52 in XYN IV; Fig. 7). The overall structure of $\mathrm{Xyn} 30 \mathrm{~B}$ is similar to the bacterial xylanases, members of GH30_8 subfamily, which is composed of a $(\alpha / \beta)_{8}$-catalytic domain formed by $8 \alpha$-helices and $\beta$ strands together with a small $\beta$-rich domain consisting of $9 \beta$-strands [26].

The catalytic glutamate residues (E165 and E253 in XynA) are conserved in all GH30 sequences. The glutamate that acts as a nucleophile in TtXyn30A sequence is located in the position 205, while the catalytic acid/ base residue is E295. Both E205 and E295 are located in conserved regions. The amino acids responsible for hydrogen bonding between XynA and MeGlcA were Y255, S258, W289, and Y295 of which only the W289 is conserved in TtXyn30A in position 338 or in position 341 for the Xyn30B. The ligand's xylose unit $(-1)$ in XynA 3D structure interacts with W113 and N164 in subsite -1 through hydrogen bonds. Both of these amino acid residues are conserved in all GH30 xylanases sequences, either of bacterial or fungal origin. The aromatic ring of W289 is also responsible for stacking interactions with the xylose unit of ligand in subsite -1 (W338 in TtXyn30A). The amino acids that form the subsite $-2 \mathrm{~b}$ of Xyn30B are conserved in TtXyn30A (R51, L299, W338, I339, T346, and S348) except for Xyn30B E345, which is Q342 (Fig. 7).

\section{Conclusions}

In summary, the present study reports the heterologous expression and characterization of a fungal GH30 xylanase designated TtXyn30A from T. thermophila. The catalytic properties of $T t \mathrm{Xyn} 30 \mathrm{~A}$ were investigated and revealed an endo-enzymatic activity that was dependent on the MeGlcA side substituent. However, the recombinant xylanase also exhibited an exo-activity against linear and decorated XOS releasing X2 units from the non-reducing end. The presented mode of action is in accordance with the recently discovered Xyn30B from T. cellulolyticus, rendering the TtXyn30A a novel GH30 xylanase with xylobiohydrolase auxiliary activity. Therefore, the difference between the catalytic properties of fungal and bacterial GH30 xylanases or even among fungal ones is not trivial. Crystal studies of TtXyn30A with an aldouronic acid as ligand are underway, as well as synergistic experiments with other hemicellulases, aiming in the understanding of the role of these unique xylanases in plant cell wall degradation.

\section{Methods}

\section{Enzymes and substrates}

EasySelect ${ }^{\mathrm{TM}}$ Pichia Expression kit and pPICZ $\alpha$ plasmid vectors were acquired from Invitrogen (Waltham, MA, USA). The restriction enzymes $C l a \mathrm{I}, \mathrm{Xba \textrm {I }}$, and $\mathrm{SacI}$ were purchased from Takara Bio Inc. (Kusatsu, Shiga Prefecture, Japan). Gel extraction and plasmid mini prep kits were both obtained from Macherey-Nagel (Düren, Germany). Beechwood xylan, wheat arabinoxylan, carob galactomannan, konjac glucomannan, barley $\beta$-glucan, 





and xylooligosaccharides (XOS) (DP 2-6) were purchased from Megazyme (Bray, Co. Wicklow, Ireland). Aldotetrauronic (terminal substitution, borohydride reduced) and aldopentauronic acids (internal substitution, borohydride reduced), and $\beta$-xylosidase from Bacillus pumilus were a kind gift from Megazyme. Endoglycosidase $\mathrm{H}$ was from New England Biolabs (Ipswich, MA, USA).

\section{Enzyme cloning and production}

The gene coding for the putative protein TtXyn30A (Protein ID 38558; chromosome 1: 7956351-7958140; accession no. XP_003660270.1), designated ex30a, was synthesized as codon optimized for expression in P. pastoris host strain X-33 and was cloned in vector pEX-K4 by GenScript (Piscataway, NJ, USA). The pPICZ $\alpha$ C Pichia vector accomplished the secreted expression of $T t \mathrm{X}$ yn30A. The pEX-K4-ex30a vector was digested with the restriction enzymes $\mathrm{ClaI}$ and $\mathrm{Xba \textrm {I }}$ and then the gel-purified fragment was inserted at the corresponding sites into the plasmid vector $\mathrm{pPICZ} \alpha \mathrm{C}$ in frame with both the yeast $\alpha$-secretion factor and the $\mathrm{C}$-term- $\mathrm{His}_{6}$ tag encoding sequences. The resulting recombinant $\mathrm{pPICZ} \alpha \mathrm{C} /$ ex30a construct was multiplied using the chemically competent Escherichia coli One Shot ${ }^{\circledR}$ Top10 (Invitrogen) cells and subsequently, the successfully transformed clones were selected based on Zeocin ${ }^{\mathrm{TM}}$ resistance $\left(25 \mu \mathrm{g} \mathrm{mL}^{-1}\right)$. Before the transformation of the ex30a gene into P. pastoris by electroporation, restriction analysis, and DNA sequencing assured its presence in the recombinant vector. $P$. pastoris was grown in shake flasks at $30{ }^{\circ} \mathrm{C}$ in a rich buffered glycerol-complex medium (BMGY) or methanol $(0.5 \%, \mathrm{v} / \mathrm{v})$ containing buffered methanolcomplex medium (BMMY) (for induction), as detailed by EasySelect ${ }^{\mathrm{TM}}$ Pichia Expression kit. For maintaining $P$. pastoris cultures and plates, yeast extract-peptone-dextrose (YPD) medium was used, while for transformants selection, YPD plates were supplemented with sorbitol (YPDS) and Zeocin ${ }^{\mathrm{TM}}$ at a final concentration of $1 \mathrm{M}$ and $100 \mu \mathrm{g} \mathrm{mL} \mathrm{m}^{-1}$, respectively.

\section{Enzyme purification}

Immobilized metal-ion affinity chromatography (IMAC) was used in order to purify the recombinant enzyme $T t$ Xyn30A after its production in P. pastoris cultures as described previously [36]. Culture supernatants were concentrated by ultrafiltration and the concentrates, after they were equilibrated with $0.02 \mathrm{M}$ Tris- $\mathrm{HCl}$ buffer (pH 8.0) containing $0.3 \mathrm{M} \mathrm{NaCl}$, were purified using an IMAC column $(1 \times 15 \mathrm{~cm}$, Talon; Clontech, Mountain View, CA, USA). Sodium dodecyl sulfate polyacrylamide gel electrophoresis (SDS-PAGE) and isoelectric focusing (IEF) were employed in order to determine the molecular weight (MW) and the isoelectric point ( $\mathrm{p} I)$ of the purified recombinant protein, respectively, as detailed previously [37]. The purified enzyme was examined for N-glycosylation through Endoglycosidase $\mathrm{H}$ treatment under denaturing conditions according to the manufacturer's instructions. Deglycosylated samples were analyzed by both SDS-PAGE and IEF. The protein concentration of the purified enzyme was determined by measuring $A_{280}$ using the recombinant xylanase's molar extinction absorptivity as it was estimated by ProtParam tool [38, 39].

\section{Enzymatic activity assays}

The enzyme activity was assayed against $0.5 \%(\mathrm{w} / \mathrm{v})$ beechwood xylan, for $30 \mathrm{~min}$ in $0.05 \mathrm{M}$ citrate-phosphate buffer $\mathrm{pH}$ 5.0. Reducing sugars that were released by beechwood xylan hydrolysis, were determined by the 3,5-dinitrosalicylic acid (DNS) method using xylose for constructing the calibration curve [40]. One unit (U) of xylanase activity was defined as the amount of enzyme that released $1 \mu \mathrm{mol}$ of reducing sugars per minute under standard assay conditions.

\section{Biochemical characterization}

The optimal temperature was determined under the standard assay procedure at temperatures ranging from 20 to $80{ }^{\circ} \mathrm{C}$ in $0.05 \mathrm{M}$ citrate-phosphate buffer ( $\mathrm{pH} 5.0$ ), while the optimal $\mathrm{pH}$ was determined at the optimal temperature over the $\mathrm{pH}$ range from 3.0 to 7.0. The $\mathrm{pH}$ stability was determined after incubating the enzyme in $0.1 \mathrm{M}$ citrate-phosphate ( $\mathrm{pH} 3.0-7.0), 0.1 \mathrm{M}$ Tris-HCl (pH 8.0-9.0), and 0.1 M glycine- $\mathrm{NaOH}(\mathrm{pH} 10.0-11.0)$ at $4{ }^{\circ} \mathrm{C}$ for $24 \mathrm{~h}$ and then measuring the residual activity employing the standard enzymatic activity assay.

The effect of various metal ions or chemical compounds $\mathrm{Ca}^{2+}, \mathrm{Co}^{2+}, \mathrm{Ni}^{2+}, \mathrm{Zn}^{2+}, \mathrm{Na}^{+}, \mathrm{K}^{+}, \mathrm{Cu}^{2+}, \mathrm{Mg}^{2+}$, $\mathrm{Mn}^{2+}, \mathrm{Fe}, \mathrm{EDTA}$, Urea, SDS) on the enzyme activity was determined by incubating the enzyme in the presence of 1,5 , and $10 \mathrm{mM}$ of the individual compounds in $0.1 \mathrm{M}$ Tris- $\mathrm{HCl}$ buffer $\mathrm{pH} 8.0$ at room temperature for $2 \mathrm{~h}$. The residual activity was then measured under standard assay conditions, in the presence of metal ions or chemical reagents, and compared to the activity of the untreated enzyme, which was taken as control (100\%).

To investigate the substrate specificity of TtXyn30A, multiple substrates, such as beechwood xylan, wheat arabinoxylan, carob galactomannan, konjac glucomannan, and barley $\beta$-glucan were selected. Enzyme activity was determined after incubation in $0.05 \mathrm{M}$ citrate-phosphate buffer $(\mathrm{pH} 4.0)$ containing $0.5 \%(\mathrm{w} / \mathrm{v})$ of each substrate at $50{ }^{\circ} \mathrm{C}$ for $30 \mathrm{~min}$. The initial velocity of the recombinant TtXyn30A was measured at $50{ }^{\circ} \mathrm{C}$ in $0.05 \mathrm{M}$ citrate-phosphate buffer ( $\mathrm{pH} 4.0$ ) with beechwood xylan 
concentrations varying from 1 to $10 \mathrm{mg} \mathrm{mL}^{-1}$. Data were fitted to the Michaelis-Menten equation to estimate the values $K_{\mathrm{m}}, V_{\text {max }}$, and $K_{\text {cat }}$, using GraphPad Prism version 6, GraphPad Software (La Jolla, CA, USA).

\section{Analysis of enzymatic hydrolysis products}

Hydrolysis products of beechwood xylan under the action of recombinant TtXyn30A were analyzed by TLC. Reaction conditions were $\mathrm{pH} 4.0$ at $50{ }^{\circ} \mathrm{C}$, substrate concentration was $0.5 \%(\mathrm{w} / \mathrm{v})$ and enzyme loading was $0.09 \mathrm{mg} \mathrm{mL}^{-1}$. Samples were taken at certain time intervals $(0.1,0.5,1.0,3.0$, and $24.0 \mathrm{~h})$ of the enzymatic reaction and were analyzed by TLC using silica gel $60 \mathrm{~F}_{254}$ plates (Merck, Darmstadt, Germany) developed twice in a solvent mixture of ethyl acetate/2-propanol/acetic acid/ formic acid/water (25:10:5:1:15 v/v). Visualization of the developed sugars was performed by spraying the TLC plates with $6.5 \mathrm{mM} \mathrm{N}$-(1-naphthyl)ethylenediamine dihydrochloride reagent in methanol containing $3 \%$ sulfuric acid [41] followed by heating at $100^{\circ} \mathrm{C}$ for $10 \mathrm{~min}$.

The analysis of the hydrolysis products was also performed employing hydrophilic interaction liquid chromatography/electrospray ionization-quadrupole time-of-flight mass spectrometry (HILIC/ESI-QTOFMS) as described previously [42]. The separation was performed at $40{ }^{\circ} \mathrm{C}$ on an ACQUITY UPLC BEH Amide column $(2.1 \times 100 \mathrm{~mm}, 1.7 \mu \mathrm{m}$; Waters Dublin, Ireland $)$ equipped with a guard column of the same packaging material. In the case of positive ionization mode (PI) the aqueous phase consisted of $\mathrm{H}_{2} \mathrm{O}$ with $1 \mathrm{mM}$ ammonium formate and $0.01 \%$ formic acid and the organic phase was $\mathrm{CH}_{3} \mathrm{CN} / \mathrm{H}_{2} \mathrm{O} 95 / 5$ with $1 \mathrm{mM}$ ammonium formate and $0.01 \%$ formic acid, while for negative ionization mode (NI) the aqueous phase consisted of $\mathrm{H}_{2} \mathrm{O}$ with $10 \mathrm{mM}$ ammonium formate and the organic phase was $\mathrm{CH}_{3} \mathrm{CN} /$ $\mathrm{H}_{2} 0$ 95/5 with $10 \mathrm{mM}$ ammonium formate. The elution gradient, for both ionization modes, started with $100 \%$ of organic phase for $2 \mathrm{~min}$, decreasing to $5 \%$ in $10 \mathrm{~min}$, and kept constant for $5 \mathrm{~min}$. The initial conditions were restored within $0.1 \mathrm{~min}$ and let to re-equilibrate for $8 \mathrm{~min}$. The flow rate was $0.2 \mathrm{~mL} \mathrm{~min}^{-1}$ and the injection volume was $5 \mu \mathrm{L}$. The QTOF system was equipped with an ESI, operating in PI and NI mode employing the following operation parameters: capillary voltage $2500 \mathrm{~V}$ (PI) and 3500 (NI); end plate offset, $500 \mathrm{~V}$; nebulizer pressure 2 bar; drying gas $8 \mathrm{~L} \mathrm{~min}^{-1}$, and gas temperature $200{ }^{\circ} \mathrm{C}$.

Hydrolysis of XOS (DP 3-6) was conducted in $0.05 \mathrm{M}$ citrate-phosphate $\mathrm{pH} 4.0$ using an enzyme load of $0.09 \mathrm{mg} \mathrm{mL}^{-1}$ at $50^{\circ} \mathrm{C}$ for up to $18 \mathrm{~h}$. To evaluate the exoaction of TtXyn30A from the non-reducing end, the XOS were treated with sodium borohydride $\left(\mathrm{NaBH}_{4}\right)$ and the $\mathrm{NaBH}_{4}$ reduced XOS were incubated with the enzyme as described for the hydrolysis of untreated XOS. To determine the hydrolysis products, the enzymatic reactions were boiled to inactivate the enzyme and then subjected to high performance anion exchange chromatography (HPAEC) equipped with an ED40 pulsed amperometric detector (PAD) (Dionex, Sunnyvale, CA, USA) using a CarboPac PA-1 $(4 \times 250 \mathrm{~mm})$ column. The elution conditions were as follows: $0-5 \mathrm{~min}, 100 \mathrm{mM} \mathrm{NaOH}$ (100\%); 5.1-30 min, $\mathrm{NaOAc}(500 \mathrm{mM})$ in $100 \mathrm{mM} \mathrm{NaOH}$ (0-20\%); 30.1-35 min, NaOAc (500 mM) in $100 \mathrm{mM}$ $\mathrm{NaOH}$ (100\%); 35.1-50 min, 100 mM NaOH (100\%).

\section{Protein sequence analysis}

The signal peptide sequence was predicted using the server SignalP 4.0 [43]. N-glycosylation and O-glycosylation sites were analyzed and predicted by NetNGlyc 1.0 and NetOGlyc 4.0 servers [44, 45]. Multiple sequence alignment of GH30 xylanases was performed using the Clustal Omega program [46] and the visualization was conducted employing the ESPript server [47].

\section{Additional files}

Additional file 1: Figure S1. Effect of $\mathrm{pH}(\mathrm{a})$ and temperature (b) on the activity of $T t X y n 30 A$ against beechwood xylan. Each data point represents the mean $\pm \mathrm{SD}(n=3)$. Figure S2. Effect of $\mathrm{pH}$ on the stability of $T$ tXyn30A. Each data point represents the mean \pm SD $(n=2)$. Figure S3. Rate of hydrolysis of beechwood xylan by TtXyn30A. Total reducing sugars were expressed as xylose equivalents. The substrate and enzyme loadings were $5 \mathrm{mg} \mathrm{mL}^{-1}$ and $0.09 \mathrm{U} \mathrm{mL}^{-1}$, respectively. Each data point represents the mean $\pm S D(n=2)$. Figure S4. Determination of hydrolysis products (a) MeGlcA ${ }^{2} X \mathrm{l}_{2}$, and (b) MeGlcA $\left.{ }^{2} X y\right|_{3}$ from beechwood glucuronoxylan under the action of TtXyn30A after $24 \mathrm{~h}$ of incubation using HILIC-ESIQTOFMS. (c) Determination of MeGlcA $\left.{ }^{2} X y\right|_{2}$ after incubation of generated UXOS with $\beta$-xylosidase. Table S1. Effect of metal ions or chemical compounds on relative activity of the recombinant TtXyn30A.

Additional file 2: Figure S1. HILIC/ESI-QTOF-MS analysis of hydrolysis products liberated from beechwood glucuronoxylan after a (a) 10 min, (b) $30 \mathrm{~min},(\mathrm{c}) 1 \mathrm{~h},(\mathrm{~d}) 3 \mathrm{~h}$, and (e) $24 \mathrm{~h}$ incubation with the TtXyn30A. The reaction was carried out in $0.05 \mathrm{mM}$ citrate-phosphate buffer $\mathrm{pH} 4.0$ at $50^{\circ} \mathrm{C}$. The substrate and enzyme loadings were $5 \mathrm{mg} \mathrm{mL}^{-1}$ and 0.09 $\mathrm{U} \mathrm{mL}^{-1}$, respectively.

\section{Abbreviations}

BMGY: buffered glycerol-complex media; BMMY: buffered methanol-complex media; DNS: 3,5-dinitrosalicylic acid; DP: degree of polymerization; GH30: glycoside hydrolase family 30; GlCA: glucuronic acid; HILIC/ESI-QTOF-MS: liquid chromatography/electrospray ionization-quadrupole time-of-flight mass spectrometry; HPAEC-PAD: high performance anion exchange chromatography-pulsed amperometric detector; IEF-PAGE: isoelectric focusing polyacrylamide gel electrophoresis; IMAC: immobilized metal-ion affinity chromatography; MeGlcA: 4-O-methyl-D-glucuronic acid; MeGlcA²Xy| 2 : aldotriuronic acid; MeGlCA $\left.{ }^{2} X y\right|_{3}$ : aldotetrauronic acid; MW: molecular weight; SDS-PAGE: sodium dodecyl sulfate polyacrylamide gel electrophoresis; TLC: thin layer chromatography; UXOS: uronic xylooligosaccharides; XOS: xylooligosaccharides; YPD: yeast extract-peptone-dextrose media; YPDS: yeast extract-peptone-dextrosesorbitol media. 


\section{Acknowledgements}

The authors would like to thank Anastasia Kritikou for her expertise in HILIC/ ESI-QTOF-MS sample analysis, and Megazyme for providing the enzyme $\beta$-xylosidase and the aldouronic acid standards.

\section{Authors' contributions}

ET conceived the project; ET and CK designed the experiments; CK and GD performed the experiments; NST performed the mass spectrometry analysis; ET and CK interpreted the data and wrote the manuscript. ET, CK, NST, and GD revised the manuscript. All authors read and approved the final manuscript.

\section{Funding}

CK and ET wish to acknowledge financial support of this research by the Greek State Scholarships Foundation (Research Projects for Excellence IKY/Siemens).

\section{Availability of data and materials}

All data generated or analyzed during this study are included in this published article and its additional information files.

\section{Ethics approval and consent to participate}

Not applicable.

\section{Consent for publication}

All authors consented on the publication of this work

\section{Competing interests}

The authors declare that they have no competing interests.

\section{Author details}

${ }^{1}$ Industrial Biotechnology \& Biocatalysis Group, School of Chemical Engineering, National Technical University of Athens, 9 Iroon Polytechniou Str., Zografou Campus, 15780 Athens, Greece. ${ }^{2}$ Laboratory of Analytical Chemistry, Department of Chemistry, National and Kapodistrian University of Athens, Panepistimioupolis Zografou, 15771 Athens, Greece. ${ }^{3}$ Biochemical and Chemical Process Engineering, Division of Sustainable Process Engineering, Department of Civil, Environmental and Natural Resources Engineering, Luleå University of Technology, 97187 Luleå, Sweden.

Received: 5 February 2019 Accepted: 29 April 2019

Published online: 11 May 2019

\section{References}

1. Saha BC. Hemicellulose bioconversion. J Ind Microbiol Biotechnol. 2003;30:279-91.

2. Scheller HV, Ulvskov P. Hemicelluloses. Annu Rev Plant Biol. 2010;61:263-89.

3. Lombard V, Golaconda Ramulu H, Drula E, Coutinho PM, Henrissat B. The carbohydrate-active enzymes database (CAZy) in 2013. Nucleic Acids Res. 2014:42:D490-5.

4. Topakas E, Panagiotou G, Christakopoulos P. Xylanases: characteristics, sources, production, and applications. In: Yang S-T, El-Enshasy HA, Thongchul N, editors. Bioprocessing technologies in biorefinery for sustainable production of fuels, chemicals, and polymers. New Jersey: Wiley; 2013. p. 147-66.

5. Biely P, Puchart V, Stringer MA, Mørkeberg Krogh KBR. Trichoderma reesei XYN VI-a novel appendage-dependent eukaryotic glucuronoxylan hydrolase. FEBS J. 2014;281:3894-903.

6. St John FJ, González JM, Pozharski E. Consolidation of glycosyl hydrolase family 30: a dual domain 4/7 hydrolase family consisting of two structurally distinct groups. FEBS Lett. 2010;584:4435-41.

7. St John FJ, Rice JD, Preston JF. Characterization of XynC from Bacillus subtilis subsp. subtilis strain 168 and analysis of its role in depolymerization of glucuronoxylan. J Bacteriol. 2006;188:8617-26.

8. Hurlbert JC, Preston JF. Functional characterization of a novel xylanase from a corn strain of Erwinia chrysanthemi. J Bacteriol. 2001;183:2093-100.

9. Vršanská M, Kolenová K, Puchart WV, Biely P. Mode of action of glycoside hydrolase family 5 glucuronoxylan xylanohydrolase from Erwinia chrysanthemi. FEBS J. 2007:274:1666-77.
10. Gallardo Ó, Fernández-Fernández M, Valls C, Valenzuela SV, Blanca Roncero M, Vidal T, et al. Characterization of a family GH5 xylanase with activity on neutral oligosaccharides and evaluation as a pulp bleaching aid. Appl Environ Microbiol. 2010;76:6290-4.

11. Valenzuela SV, Diaz P, Pastor FIJ. Modular glucuronoxylan-specific xylanase with a family CBM35 carbohydrate-binding module. Appl Environ Microbiol. 2012;78:3923-31.

12. Maehara T, Yagi H, Sato T, Ohnishi-Kameyama M, Fujimoto Z, Kamino $\mathrm{K}$, et al. Characterization of a GH30 glucuronoxylan specific xylanase from Streptomyces turgidiscabies C56. Appl Environ Microbiol. 2017;84:e01850-17.

13. Guo Y, Gao Z, Xu J, Chang S, Wu B, He B. A family 30 glucurono-xylanase from Bacillus subtilis LC9: expression, characterization and its application in Chinese bread making. Int J Biol Macromol. 2018;117:377-84.

14. St John FJ, Dietrich D, Crooks C, Pozharski E, González JM, Bales E, et al. A novel member of glycoside hydrolase family 30 subfamily 8 with altered substrate specificity. Acta Crystallogr Sect D Biol Crystallogr. 2014:70:2950-8.

15. St John FJ, Dietrich D, Crooks C, Balogun P, de Serrano V, Pozharski E, et al. A plasmid borne, functionally novel glycoside hydrolase family 30 subfamily 8 endoxylanase from solventogenic Clostridium. Biochem J. 2018;475:1533-51.

16. Tenkanen M, Vršanská M, Siika-Aho M, Wong DW, Puchart V, Penttilä M, et al. Xylanase XYN IV from Trichoderma reesei showing exo- and endoxylanase activity. FEBS J. 2013;280:285-301.

17. Luo H, Yang J, Li J, Shi P, Huang H, Bai Y, et al. Molecular cloning and characterization of the novel acidic xylanase XYLD from Bispora sp. MEY-1 that is homologous to family 30 glycosyl hydrolases. Appl Microbiol Biotechnol. 2010:86:1829-39.

18. Nordberg Karlsson E, Schmitz E, Linares-Pastén JA, Adlercreutz P. Endoxylanases as tools for production of substituted xylooligosaccharides with prebiotic properties. Appl Microbiol Biotechnol. 2018;102:9081-8.

19. Rhee MS, Wei L, Sawhney N, Rice JD, St John FJ, Hurlbert JC, et al. Engineering the xylan utilization system in Bacillus subtilis for production of acidic xylooligosaccharides. Appl Environ Microbiol. 2014;80:917-27.

20. Wei L, Rhee MS, Preston JF, Chen H. Production of acidic xylooligosaccharides from methylglucuronoarabinoxylans by Bacillus subtilis strain MR44. J Chem Technol Biotechnol. 2016;91:2056-62.

21. Valls C, Pastor FIJ, Vidal T, Roncero MB, Díaz P, Martínez J, et al. Antioxidant activity of xylooligosaccharides produced from glucuronoxylan by Xyn10A and Xyn30D xylanases and eucalyptus autohydrolysates. Carbohydr Polym. 2018;194:43-50.

22. Turner P, Mamo G, Karlsson EN. Potential and utilization of thermophiles and thermostable enzymes in biorefining. Microb Cell Fact. 2007;6:9.

23. Karnaouri A, Topakas E, Antonopoulou I, Christakopoulos P. Genomic insights into the fungal lignocellulolytic system of Myceliophthora thermophila. Front Microbiol. 2014;5:1-22.

24. Ustinov BB, Gusakov AV, Antonov Al, Sinitsyn AP. Comparison of properties and mode of action of six secreted xylanases from Chrysosporium lucknowense. Enzyme Microb Technol. 2008;43:56-65.

25. van Gool MP, van Muiswinkel GCJ, Hinz SWA, Schols HA, Sinitsyn AP, Gruppen $\mathrm{H}$. Two novel GH11 endo-xylanases from Myceliophthora thermophila C1 act differently toward soluble and insoluble xylans. Enzyme Microb Technol. 2013;53:25-32

26. Nakamichi Y, Fouquet T, Ito S, Watanabe M, Matsushika A, Inoue H. Structural and functional characterization of a bifunctional GH30-7 xylanase $B$ from the filamentous fungus Talaromyces cellulolyticus. J Biol Chem. 2019:294:4065-78.

27. Espinoza K, Eyzaguirre J. Identification, heterologous expression and characterization of a novel glycoside hydrolase family 30 xylanase from the fungus Penicillium purpurogenum. Carbohydr Res. 2018;468:45-50.

28. Padilha IQM, Valenzuela SV, Grisi TCSL, Diaz P, De Araújo DAM, Javier Pastor FI. A glucuronoxylan-specific xylanase from a new Paenibacillus favisporus strain isolated from tropical soil of Brazil. Int Microbiol. 2015;17:175-84.

29. Daly R, Hearn MTWW. Expression of heterologous proteins in Pichia pastoris: a useful experimental tool in protein engineering and production. J Mol Recognit. 2005;18:119-38.

30. Cohen R, Suzuki MR, Hammel KE. Processive endoglucanase active in crystalline cellulose hydrolysis by the brown rot basidiomycete Gloeophyllum trabeum. Appl Environ Microbiol. 2005;71:2412-7. 
31. Verma AK, Goyal A. A novel member of family 30 glycoside hydrolase subfamily 8 glucuronoxylan endo- $\beta-1,4-x y l a n a s e(C t X y n G H 30)$ from Clostridium thermocellum orchestrates catalysis on arabinose decorated xylans. J Mol Catal B Enzym. 2016;129:6-14.

32. St John FJ, Godwin DK, Preston JF, Pozharski E, Hurlbert JC. Crystallization and crystallographic analysis of Bacillus subtilis xylanase C. Acta Crystallogr Sect F Struct Biol Cryst Commun. 2009;65:499-503.

33. Urbániková Ä, Vršanská M, Mørkeberg Krogh KBR, Hoff T, Biely P. Structural basis for substrate recognition by Erwinia chrysanthemi GH30 glucuronoxylanase. FEBS J. 2011;278:2105-16.

34. Sainz-Polo MA, Valenzuela SV, González B, Pastor FIJ, Sanz-Aparicio J. Structural analysis of glucuronoxylan-specific Xyn30D and its attached CBM35 domain gives insights into the role of modularity in specificity. J Biol Chem. 2014;289:31088-101

35. Freire F, Verma A, Bule P, Alves VD, Fontes CMGA, Goyal A, et al. Conservation in the mechanism of glucuronoxylan hydrolysis revealed by the structure of glucuronoxylan xylanohydrolase (CtXyn30A) from Clostridium thermocellum. Acta Crystallogr Sect D Struct Biol. 2016;72:1162-73.

36. Katsimpouras C, Bénarouche A, Navarro D, Karpusas M, Dimarogona M, Berrin J-G, et al. Enzymatic synthesis of model substrates recognized by glucuronoyl esterases from Podospora anserina and Myceliophthora thermophila. Appl Microbiol Biotechnol. 2014;98:5507-16.

37. Karnaouri AC, Topakas E, Christakopoulos P. Cloning, expression, and characterization of a thermostable GH7 endoglucanase from Myceliophthora thermophila capable of high-consistency enzymatic liquefaction. Appl Microbiol Biotechnol. 2014;98:231-42.

38. Stoscheck CM. Quantitation of protein. Methods Enzymol. 1990;182:50-68

39. Gasteiger E, Gattiker A, Hoogland C, Ivanyi I, Appel RD, Bairoch A. ExPASy: the proteomics server for in-depth protein knowledge and analysis. Nucleic Acids Res. 2003:31:3784-8.
40. Miller GL. Use of dinitrosalicylic acid reagent for determination of reducing sugar. Anal Chem. 1959;31:426-8.

41. Bounias M. N-(1-naphthyl)ethylenediamine dihydrochloride as a new reagent for nanomole quantification of sugars on thin-layer plates by a mathematical calibration process. Anal Biochem. 1980;106:291-5.

42. Gago-Ferrero P, Schymanski EL, Bletsou AA, Aalizadeh R, Hollender J, Thomaidis NS. Extended suspect and non-target strategies to characterize emerging polar organic contaminants in raw wastewater with LC-HRMS/MS. Environ Sci Technol. 2015;49:12333-41.

43. Petersen TN, Brunak S, von Heijne G, Nielsen H. SignalP 4.0: discriminating signal peptides from transmembrane regions. Nat Methods. 2011;8:785-6.

44. Blom N, Sicheritz-Pontén T, Gupta R, Gammeltoft S, Brunak S. Prediction of post-translational glycosylation and phosphorylation of proteins from the amino acid sequence. Proteomics. 2004;4:1633-49.

45. Steentoft C, Vakhrushev SY, Joshi HJ, Kong Y, Vester-Christensen MB, Schjoldager KT-BG, et al. Precision mapping of the human O-GalNAc glycoproteome through SimpleCell technology. EMBO J. 2013;32:1478-88.

46. Sievers F, Wilm A, Dineen D, Gibson TJ, Karplus K, Li W, et al. Fast, scalable generation of high-quality protein multiple sequence alignments using Clustal Omega. Mol Syst Biol. 2011;7:539.

47. Robert X, Gouet P. Deciphering key features in protein structures with the new ENDscript server. Nucleic Acids Res. 2014;42:W320-4.

\section{Publisher's Note}

Springer Nature remains neutral with regard to jurisdictional claims in published maps and institutional affiliations.
Ready to submit your research? Choose BMC and benefit from:

- fast, convenient online submission

- thorough peer review by experienced researchers in your field

- rapid publication on acceptance

- support for research data, including large and complex data types

- gold Open Access which fosters wider collaboration and increased citations

- maximum visibility for your research: over $100 \mathrm{M}$ website views per year

At BMC, research is always in progress.

Learn more biomedcentral.com/submissions 